\title{
CONCEPČ̃̃O, TRAJETÓRIA E AVALIAÇÃO DE UM MESTRADO PROFISSIONAL EM EDUCAÇÃO
}

SUELI SOARES DOS SANTOS BATISTA'

MARÍLIA MACORIN AZEVEDO"

EMERSON FREIRE"'

I Centro Estadua de Educação Tecnológica Paula Souza (Ceeteps), São Paulo-SP, Brasil; http:// orcid.org/0000-0001-81269615; suelissbatista@uol.com.br

II Centro Estadual de Educação Tecnológica Paula Souza (Ceeteps) São Paulo-SP, Brasil: marilia.azevedo@fatec.sp.gov.br

III Centro Estadua de Educação Tecnológica Paula Souza (Ceeteps) São Paulo-SP, Brasil; http://orcid.org/00000001-5449-2002;

freire.emerson@uol.com.br

\section{RESUMO}

A articulação da formação e da atuação docente à sua profissionalização tem sido um debate profícuo entre aqueles que têm atuado nos mestrados profissionais em educação e refletido sobre $o$ alcance dessa modalidade de pós-graduação. O presente estudo foi concebido no contexto atual de implementação, consolidação e avaliação desses mestrados, contexto esse no qual os autores deste artigo estão inseridos. A partir de pesquisa bibliográfica, documental e de levantamento quantitativo e qualitativo quanto ao programa do qual participam, os autores fazem a caracterização não só dos mestrandos, mas também da natureza dos resultados obtidos com as primeiras dissertações concluídas, apresentando desafios e possibilidades.

PALAVRAS-CHAVE MESTRAdO PROFISSIONAL EM EDUCAÇÃO • EDUCAÇÃO PROFISSIONAL E TECNOLÓGICA • PÓS-GRADUAÇÃO - AVAliação da Educação. 


\title{
CONCEPCIÓN, TRAYECTORIA Y EVALUACIÓN DE UNA MAESTRÍA PROFESIONAL EN EDUCACIÓN \\ RESUMEN
}

La articulación de la formación y la actuación docente a su profesionalización ha sido un debate proficuo entre aquellos que han actuado en las maestrías profesionales en educación y han reflexionado sobre el alcance de esa modalidad de postgrado. El presente estudio fue concebido en el actual contexto de implementación, consolidación y evaluación de tales maestrías, contexto en el que los autores de este artículo están insertados. A partir de una investigación bibliográfica, documental y de relevamiento cuantitativo y cualitativo en lo que concierne al programa en el que participan, los autores caracterizan no solo a los alumnos del curso, sino también a la naturaleza de los resultados obtenidos con las primeras disertaciones concluidas, presentando desafios $y$ posibilidades.

PALABRAS CLAVE MAESTRÍA PROFESIONAL EN EDUCACIÓN • EDUCACIÓN PROFESIONAL Y TECNOLÓGICA • POSTGRADO • EVALUACIÓN DE LA EDUCACIÓN.

\section{DESIGN, TRAJECTORY AND EVALUATION OF A MASTERS IN EDUCATION}

\begin{abstract}
Linking teacher training and practice to professionalism has been a fruitful discussion among those who have contributed to the development of professional masters in education and reflected on the scope of this type of post-graduation. This study was designed in the current context of implementation, consolidation and evaluation of these master's programs, in which the authors of this article are involved. Based on bibliographical and documentary research, as well as on the quantitative and qualitative survey of the programs they participate in, these authors aim to characterize not only the master students themselves, but also the nature of the results obtained in the first dissertations on the subject, by presenting challenges and possibilities.

KEYWORDS PROFESSIONAL MASTER'S DEGREES IN EDUCATION • PROFESSIONAL AND TECHNOLOGICAL EDUCATION - GRADUATE STUDIES - EVALUATION OF EDUCATION.
\end{abstract}




\section{INTRODUÇÃO}

Os mestrados profissionais trazem para a pós-graduação desafios relativos à natureza e objetivos da pesquisa e também ao que se entende como profissionalização. É mediante algo conflitante como essa categoria de mestrado que são confrontadas as convicções dos pesquisadores, dos programas de pós-graduação, as concepções que opõem e hierarquizam a formação propedêutica e a formação profissional, a teoria e a prática e a pesquisa e a prática docente. Nesse sentido, o embate para definir, implementar e consolidar os mestrados profissionais também diz respeito à maneira como a pós-graduação em geral tem sido pensada, colocando, muitas vezes, a dimensão acadêmica como distante do mundo do trabalho, das práticas profissionais e da produção técnica.

O Ministério da Educação (MEC), em portaria específica, proclama que, entre os objetivos dos mestrados profissionais, está a promoção da "articulação integrada da formação profissional com entidades demandantes de naturezas diversas", a melhora da "eficácia e [d]a eficiência das organizações públicas e privadas por meio da solução de problemas 
e geração e aplicação de processos de inovação apropriados" (COORDENAÇÃO DE APERFEIÇOAMENTO DE PESSOAL DE NÍVEL SUPERIOR - CAPES, 2009, p. 21). A área de educação, na oferta dos mestrados profissionais, apresenta especificidades que dialogam com os objetivos propostos para essa modalidade de pós-graduação, contribuindo com a sua construção a partir das trajetórias desses programas.

Quando a discussão se volta para os mestrados profissionais em educação (MPE), esse aspecto ganha contornos específicos para a formação e atuação docente, como considera Fischer (2005) ao associá-los com a modalidade acadêmica de mestrados não necessariamente vinculados à produção técnica ou tecnológica e à realidade profissional de seus ingressantes e egressos. Esse tipo de análise não deve levar à ideia de que os mestrados profissionais não tenham também seu caráter acadêmico e nem que os mestrados acadêmicos não tenham papel importante na formação de quadros profissionais. Analisando os mestrados profissionais como prática acadêmica, entende-se que o desafio é pensar por inclusão qualificada e não por exclusão.

É necessário que esses programas estejam atentos aos critérios de seleção para ingresso de seus mestrandos e a como se realiza a interlocução com seus egressos, no sentido de compreender e avaliar a viabilidade das possíveis intervenções concebidas nos trabalhos de conclusão do curso como aspecto fundamental de uma pós-graduação na modalidade profissional. Na ponta do processo, alguns mestrados profissionais em educação têm realizado estudos para saber como os ingressantes e egressos desses cursos percebem a articulação entre a pesquisa realizada e a sua prática profissional. Isso é possível perceber na publicação de dossiês temáticos em revistas da área de educação a partir de 2016 (NOGUEIRA; NERES; BRITO, 2016; SOUSA; PLACCO, 2016; FIALHO; HETKOWSKI, 2017).

Os autores deste estudo são docentes pesquisadores vinculados ao Programa de Mestrado Profissional em Educação oferecido pelo Centro Estadual de Educação Tecnológica Paula Souza (Ceeteps) e se propõem, neste artigo, a partir de pesquisa bibliográfica, documental e de dados quantitativos, 
a contribuir com esse debate, considerando a especificidade da concepção e trajetória desse programa de pós-graduação na modalidade profissional. Acredita-se que é fundamental, no estágio em que os MPEs se encontram, adensar as discussões para um melhor delineamento da pesquisa nos mestrados profissionais, em suas concepções e no desenvolvimento de intervenções possíveis, e a vinculação desses mestrados com a atuação profissional dos seus egressos.

\section{MESTRADOS PROFISSIONAIS E OS DESAFIOS PARA A PÓS-GRADUAÇÃO EM EDUCAÇÃO}

Marcados inicialmente por muitas controvérsias, impasses, resistências e desconfianças, os mestrados profissionais, e especificamente os MPEs, têm alcançado importante espaço nas políticas de pós-graduação (ANDRÉ; PRINCEPE, 2017; CUNHA; AGRANIONIH, 2017).

A despeito de resistências, os mestrados profissionais acenam para uma compreensão mais integrada e ampla das relações entre pesquisa e profissionalização. No caso dos MPEs, essa compreensão recai sobre a formação docente, sobre o currículo, as políticas e programas educacionais. Como afirmam Romão e Mafra (2016), as marcas distintivas desse tipo de pós-graduação são a pesquisa, a reflexão e a construção de inteligência sobre a formação profissional.

Fischer (2005), problematizando a formação acadêmica a partir do surgimento dos mestrados profissionais, aponta para aspectos dessa modalidade de pós-graduação em seu processo de implementação e consolidação, aspectos esses ainda não totalmente resolvidos. Ainda há debates relevantes no que diz respeito ao público-alvo dos mestrados profissionais, à natureza da produção resultante das pesquisas realizadas e à relevância social dessa produção no contexto amplo da profissionalização e do mundo do trabalho. O Fórum Nacional de Coordenadores de Programas de Pós-Graduação em Educação (Forpred), em documento produzido em 2013, declara que mestrados profissionais não são cursos não acadêmicos, já que existem principalmente nos espaços da academia (2013, p. 9). Uma das dificuldades é entender 
que um mestrado profissional não objetiva colocar em questão os mestrados acadêmicos, mas contribuir para dar um novo sentido para a profissionalização como algo relevante nas políticas de pós-graduação.

De qualquer forma, sem desconsiderar as diretrizes educacionais, mas incorporando-as à sua maneira, os programas de pós-graduação que oferecem os MPEs têm caminhado na direção de construir a sua identidade como espaços de formação do profissional-educador-pesquisador para atuar nos processos educativos (FORPRED, 2013; CUNHA; AGRANIONIH, 2017).

A construção dessa identidade passa inevitavelmente pela discussão em torno do conteúdo das dissertações desenvolvidas no contexto desses mestrados. O trabalho de conclusão de um mestrado profissional foi normatizado pela Capes na Portaria n. 17, de 2009. Esse documento prevê a elaboração desses trabalhos considerando uma multiplicidade de formatos, como dissertações, artigos, patentes, projetos técnicos, desenvolvimento de aplicativos, materiais didáticos e instrucionais, entre outros (CAPES, 2009, p. 21).

Analisando a documentação que inaugura os mestrados profissionais, Romão e Mafra (2016) ainda consideram que não se associa diretamente setor produtivo com mundo do trabalho, havendo nuances que precisam ser matizadas nos MPEs, e, nesse sentido, a natureza do "produto" resultante não é idêntica à dos mestrados profissionais de qualquer outra área (ALMEIDA, 2016), sendo necessário considerar a especificidade da área de educação. Hetkowski e Dantas (2016), procurando enquadrar essas diretrizes aos MPEs, afirmam que é possível construir trabalhos de conclusão desses mestrados de forma a contemplar a realidade educacional, envolvendo professores, alunos e comunidade.

Assim, André e Princepe (2017) defendem que, nos MPEs, é fundamental que o profissional da educação seja um pesquisador da sua prática, estando toda a formação orientada para a pesquisa promotora da reflexão crítica dessa prática profissional. Com argumentos dessa natureza, outros autores envolvidos com Programas de MPEs delineiam a identidade desses mestrados não como oposição ao acadêmico, mas 
como posse de um efetivo compromisso e vínculo com os espaços e as trajetórias profissionais de seus mestrandos. Esse compromisso e vínculo com a profissionalização e a formação permanente desses profissionais da educação é que dão contornos aos MPEs na perspectiva da formação de professores reflexivos, pesquisadores e intelectuais críticos (CAMPOS; GUÉRIOS, 2017).

\section{MESTRADO PROFISSIONAL EM EDUCAÇÃO E A EDUCAÇÃO PROFISSIONAL E TECNOLÓGICA}

Peterossi e Menino (2017) afirmam que, na tendência de agrupar todos os professores e de tentar criar uma identidade profissional comum, deixa-se de perceber o que é próprio da formação e da atuação do docente do ensino técnico. Essa especificidade não pode ser tratada simplesmente a partir de propostas de estratégias, práticas dissociadas de uma reflexão mais ampla sobre as políticas educacionais. Também não pode ser tratada apenas de maneira generalista, que é capaz de provocar problematizações, mas não aproximações do cotidiano de formação e atuação desses docentes.

Para Machado (2011), essa especificidade que se inscreve na heterogeneidade de natureza institucional, situacional e de trajetória profissional dos docentes da Educação Profissional e Tecnológica (EPT) precisa ser levada em conta pelas políticas de formação inicial e continuada destinadas a esses docentes.

O Ceeteps oferece desde 2014 o Programa de Mestrado Profissional em Gestão e Desenvolvimento da Educação Profissional, cujo objetivo é buscar uma efetiva interferência na realidade da EPT por meio do processo de formação de professores e gestores e do desenvolvimento na área. Como lócus privilegiado deste estudo, passamos a detalhar e discutir aspectos importantes da concepção, trajetória e primeiros resultados desse Programa. 


\section{PROGRAMA DE MESTRADO PROFISSIONAL EM GESTÃO E DESENVOLVIMENTO DA EDUCAÇÃO PROFISSIONAL DO CEETEPS}

O Ceeteps é uma autarquia do governo do estado de São Paulo, vinculada à Secretaria de Desenvolvimento Econômico, Ciência, Tecnologia e Inovação (SDECTI). Presente em aproximadamente 300 municípios, a instituição administra 221 escolas técnicas (Etecs) e 68 faculdades de tecnologia (Fatecs) estaduais, ultrapassando o número de $290 \mathrm{mil}$ alunos em cursos técnicos de nível médio e superiores tecnológicos. As Etecs atendem mais de 211 mil estudantes nos ensinos técnico, médio e técnico integrado ao médio, com 139 cursos técnicos para os setores industrial, agropecuário e de serviços, incluindo habilitações nas modalidades presencial, semipresencial, on-line, Educação de Jovens e Adultos (EJA) e especialização técnica. As Fatecs têm mais de 80 mil alunos matriculados em 73 cursos de graduação tecnológica, em diversas áreas, como Construção Civil, Mecânica, Tecnologia da Informação, Turismo, entre outras. Além da graduação, são oferecidos cursos de pós-graduação, atualização tecnológica e extensão (CEETEPS, 2017).

Um mestrado profissional com enfoque em EPT vai ao encontro do escopo e da vocação da instituição, que busca o conhecimento associado à profissionalização como não meramente instrumental. O Programa em questão vem de uma experiência acumulada da instituição num Programa anterior, credenciado em 2002, com o enfoque em Tecnologia, Gestão, Desenvolvimento e Formação Profissional. Passados dez anos dessa experiência, a instituição formou dois outros programas com especificidades mais delineadas: o Mestrado Profissional em Gestão e Tecnologia em Sistemas Produtivos, na área de Engenharias III, e o Mestrado Profissional em Gestão e Desenvolvimento da Educação Profissional, na área de Educação (CEETEPS, 2013).

Esse Programa de Mestrado Profissional em Gestão e Desenvolvimento da Educação Profissional, cuja primeira turma ingressou em março de 2015, em seu projeto inicial, anunciou ter como objetivo buscar uma efetiva interferência na realidade da EPT por meio do processo de formação de 
professores e gestores e do desenvolvimento de práticas inovadoras no processo de ensino-aprendizagem. Seu propósito é contribuir para que se esboce uma concepção de EPT que não seja apenas uma combinação da lógica do setor produtivo com práticas educativas e para que, sim, contemple as dimensões socioculturais no contexto dos desafios da época atual. Daí sua área de concentração ser Educação e Trabalho (CEETEPS, 2013).

Contando com um quadro de cerca de 13.000 professores e 5.000 funcionários acadêmicos e administrativos, egressos ao longo dos seus 46 anos de existência, o Ceeteps apresenta uma demanda interna importante, cuja oferta de um MPE visa a atender. Mas há também demandas externas, como a necessária formação de formadores no ambiente de trabalho mediante as mudanças dos antigos conceitos de treinamento para os conceitos mais complexos de educação corporativa e organizacional. O MPE oferecido pelo Ceeteps também corrobora a sua inclusão societária, marcada por parcerias com outras instituições de educação profissional, como o Sistema S e a Rede Federal de EPT, além das parcerias com o setor produtivo. A formação dos tecnólogos docentes e a necessária problematização e inserção de novas tecnologias na educação estão no horizonte do MPE como cenário de pesquisa e de intervenção em que há a redefinição da EPT.

Desde seu início, com algumas alterações, o Programa se mantém com 12 professores permanentes, atuando em dedicação exclusiva, e um professor colaborador. Dentro de sua área de concentração, Educação e Trabalho, apresenta duas linhas de pesquisa intituladas Formação do Formador e Gestão e Avaliação. Três grupos de pesquisa norteiam a seleção dos candidatos. Esses grupos de pesquisa, formados por docentes e discentes do Programa, são intitulados Políticas Públicas para Educação Profissional, Fundamentos e Práticas da Educação Profissional e Sistemas Gestores e Avaliação. É importante destacar que, decorridos os três anos iniciais do Programa, a estruturação desses grupos passa por reformulação, abrindo caminhos para outros formatos e mesmo para a criação de outros grupos. 


\section{CARACTERIZAÇÃO DE CANDIDATOS E MESTRANDOS DO PROGRAMA DO CEETEPS (2015-2017)}

Estando em curso a avaliação da Capes quanto aos MPEs, torna-se necessário compreender a construção da identidade desses mestrados por meio de suas linhas de pesquisa, propostas curriculares e dos trabalhos finais de conclusão voltados para a atividade profissional dos mestrandos. Essa compreensão nem sempre está associada à temporalidade dessa avaliação, tendo os MPEs que construírem sua identidade e se consolidarem de maneira articulada e ininterrupta.

Como ação de curto prazo, o projeto do Programa que ora analisamos prevê um processo de avaliação interna para "aferir o cumprimento das metas de produção acadêmica anual dos docentes e discentes em consonância com as exigências da Capes” (CEETEPS, 2013, p. 9).

O presente estudo faz parte desse esforço institucional visando não somente às importantes questões diretamente ligadas aos indicadores de produtividade, mas também à construção da identidade desse mestrado, que se dá também pelo seu processo de seleção dos candidatos e o perfil do mestrando que tem formado, bem como pela natureza dos projetos desenvolvidos e das dissertações concluídas.

Com esse objetivo, no primeiro semestre de 2017, foi realizada uma análise estatística utilizando-se dados coletados das fichas de inscrição dos candidatos ao Programa nos anos de 2015, 2016 e 2017. A ferramenta utilizada foi a análise estratificada, que investiga os dados em diferentes estratos. Os dados anuais foram coletados e analisados ano a ano e depois comparados levando em conta o período em questão e algumas dimensões consideradas importantes para esse esforço de autoavaliação. Essas dimensões se referem ao gênero, à faixa etária, à instituição onde o candidato fez a graduação e à sua atuação profissional. As informações para compreender essas dimensões foram coletadas e analisadas procurando-se fazer o contraponto entre inscritos e aprovados.

Analisando-se os três processos seletivos consecutivos, observa-se um número crescente de inscritos para um universo de 25 vagas anuais (Tabela 1 ). 
TABELA 1 - Quantidade de candidatos em todas as etapas do processo seletivo

\begin{tabular}{c|c|c|c}
\hline CANDIDATOS & $\mathbf{2 0 1 5}$ & $\mathbf{2 0 1 6}$ & $\mathbf{2 0 1 7}$ \\
\hline Inscritos & 73 & 105 & 122 \\
\hline Deferidos & 54 & 75 & 89 \\
\hline Aprovados & 25 & 24 & 25 \\
\hline
\end{tabular}

Fonte: Elaboração dos autores.

As inscrições indeferidas se devem a diversos fatores de natureza documental. Mas a exigência da certificação em inglês tem sido um fator decisivo de indeferimento, na medida em que essa certificação é um dos pré-requisitos para a realização da inscrição. Cerca de $60 \%$ dos candidatos têm suas inscrições indeferidas por não conseguirem comprovar a proficiência no inglês. Uma outra barreira para os candidatos depois de deferidas as inscrições é a prova de português eliminatória, na qual ficaram reprovados nesse período cerca de $50 \%$ dos candidatos. A prova, versando sobre a temática da educação profissional e tecnológica, busca avaliar a capacidade do candidato em compreender um texto e desenvolver argumentação coerente e coesa diante do que é apresentado como proposta de leitura e escrita.

Ao longo desses três anos de processo seletivo, verificou-se a predominância de mulheres tanto entre os inscritos quanto entre os aprovados. Analisando-se os dados de faixa etária das inscrições deferidas, observa-se uma concentração de candidatos entre 30 e 50 anos, com destaque para o ano de 2017, quando houve maior incidência de candidatos entre 30 e 40 anos. Pode-se perceber, pelos dados obtidos e analisados, que candidatos com mais de 60 anos participaram dos processos de 2016 e 2017, porém sem aprovação. No ano de 2015, primeiro processo seletivo do programa, observou-se uma maior incidência de candidatos aprovados na faixa etária de 40 e 50 anos. Candidatos com faixa etária entre 30 e 40 anos se destacaram nos três processos seletivos entre os aprovados em 2017.

Ao analisar os dados relativos à instituição em que os inscritos e aprovados fizeram o seu curso de graduação, percebe-se a incidência de egressos de universidades particulares. 
Egressos da Universidade de São Paulo (USP), das Fatecs e de faculdades particulares aparecem em menor número em todos os momentos dos processos de seleção ao longo desses primeiros três anos.

Uma leitura inicial das fichas de inscrição dos candidatos inscritos e aprovados permitiu criar categorias associadas ao seu exercício profissional. Assim, aparecem na análise docentes, empresários, coordenadores(as) e diretores(as) de unidades escolares, funcionários(as) da administração do Ceeteps e categorias profissionais diversas, como analistas de sistemas, bibliotecários(as) e advogados(as), que foram enquadradas como outros para fins de levantamento e análise estatística.

Entre os inscritos deferidos no período de 2015 a 2017, tivemos a presença de 164 docentes em um universo de 218 inscritos, o que equivale a $75 \%$ das inscrições. A categoria docentes é a única que tem crescido ininterruptamente em termos de número de inscrições. Seguindo a mesma tendência, entre os candidatos aprovados, também há incidência maior de docentes, como era de se esperar pelas características do Programa e da trajetória da instituição. Podemos inferir que a profissão docente tem obtido um destaque significativo em relação a profissões gerenciais e administrativas. Também se observou um leve destaque dos candidatos que estavam exercendo funções administrativas no Ceeteps. Quando se analisa a atuação profissional dos candidatos que atuam na administração central do Ceeteps, percebe-se também a incidência de professores que são deslocados para exercer esse tipo de função. Dos 74 aprovados entre 2015 e 2017, 48 são docentes, 4 deles atuando como coordenadores e/ou diretores de unidades escolares do Ceeteps, 9 trabalhando na administração central da instituição e mais 13 aprovados enquadrados na categoria outros.

Parece-nos evidente que o acesso ao Programa por parte dos docentes se dá não somente pelo desempenho específico de cada candidato, da inscrição às etapas finais do processo, mas também pela necessidade de o Programa incorporar alunos que garantam maiores índices de produtividade (acadêmica). Essa é uma das contradições dos mestrados 
profissionais interessante de se observar, na medida em que a avaliação da Capes recai muito sobre a produção de artigos em revistas com bom Qualis. Esse critério de avaliação acaba se refletindo no processo de seleção dos candidatos que já mostram um bom desempenho acadêmico ou têm condições de vir a tê-lo, lembrando que faz parte das etapas finais do processo de seleção a análise do projeto e do currículo Lattes do candidato, não sendo aceitos outros formatos de currículo.

Percebe-se, assim, a prevalência dos candidatos que atuam especificamente na área de educação. Detalhando um pouco mais esses dados, nota-se que, na categoria outros, aparecem mestrandos que fazem parte do corpo técnico-administrativo do Instituto Federal de São Paulo (IFSP) - Câmpus SP, totalizando quatro funcionários alocados em áreas diversas. Se olharmos para esses dados procurando a área de atuação, sendo os indivíduos docentes ou não, percebemos que, entre os 74 aprovados de 2015 a 2017, 56 atuam na área de educação em instituições públicas e privadas, em cargos de docência ou técnico-administrativos, perfazendo quase $76 \%$ dos mestrandos.

Isso significa que, embora o público-alvo definido no projeto do Programa também inclua indivíduos atuando em contextos de treinamento para as demandas atuais de educação corporativa e organizacional, esse contingente ainda é bastante tímido nos três anos iniciais de seleção de candidatos. Mestrandos oriundos de instituições públicas ou privadas não vinculadas à educação totalizaram 15 num universo de 74 aprovados. Esse resultado é muito próximo quando se analisa o universo de candidatos inscritos, denotando que essa demanda externa à área específica da educação em geral, mas muito vinculada à história do Ceeteps enquanto instituição de educação profissional, necessita de estudos e intervenções. É preciso compreender, por um lado, como o setor produtivo e o mundo corporativo têm se posicionado em relação à oferta dos mestrados profissionais. Em contrapartida, verificamos, em outras instituições que oferecem esse tipo de pós-graduação, a busca de parcerias com instituições privadas e públicas visando a atender funcionários da área técnico-administrativa dessas instituições. Essa é uma intervenção possível quando se pensa no contexto de um 
mestrado profissional estreitamente vinculado à educação profissional e tecnológica.

Candidatos oriundos de universidades (públicas ou privadas) têm desempenho melhor que os oriundos de outras instituições. A prova escrita, sendo eliminatória, potencializa esse indicador ao selecionar candidatos com formação de leitura e escrita mais acadêmica e que não subsumam esse tipo de formação à educação estritamente técnica. A presença de profissionais formados pelas Fatecs nos leva a um dado interessante quanto à procura de tecnólogos (docentes ou não). Verificando os dados dos candidatos aprovados no período em questão, identificamos a presença de 14 tecnólogos, sendo, entre esses, sete formados pelo Ceeteps. Embora em seu projeto o Programa mencione o necessário atendimento a uma demanda interna, que é o prosseguimento dos estudos em nível de pós-graduação de seus egressos tecnólogos, a maior parte dos interessados e aprovados no processo de seleção são de universidades e faculdades privadas, o que aponta para reflexões que podem gerar estudos futuros, tais como a relevância da pesquisa na formação do tecnólogo e/ou o incentivo para a continuidade de estudos de pós-graduação stricto sensu pelas instituições em que atuam, inclusive considerando estratégias e oportunidades de formação continuada criadas pelo próprio Ceeteps.

Algo que se observa entre os candidatos aprovados é que há uma variedade de formações iniciais não vinculadas a cursos de licenciatura, o que torna esse mestrado um espaço de formação para esses docentes tecnólogos ou bacharéis. Entre os 74 aprovados, apenas 11 candidatos declararam ter realizado curso de licenciatura, o que caracteriza a maioria desses docentes mestrandos como indivíduos que têm no programa em tela a oportunidade de aprofundar e até iniciar de maneira mais sistemática os seus estudos sobre a área de educação e especificamente da educação profissional.

\section{DISSERTAÇÕES DA PRIMEIRA TURMA DE EGRESSOS (2015)}

Da primeira turma do Programa, entre os 23 egressos, 14 são docentes e funcionários técnico-administrativos vinculados 
ao Ceeteps. Essa vinculação profissional e institucional, que é uma tendência comum e até desejada para os MPES, inevitavelmente se reflete nos trabalhos de conclusão no formato de dissertações. A experiência desse MPE mostra que o caráter profissional não se dá pelo formato do trabalho de conclusão. A predominância da formação dos profissionais da educação, o conhecimento, o reconhecimento dessa predominância e o constante entrelaçamento entre a vinculação profissional e a natureza da pesquisa produzida são as marcas distintivas de um MPE e não necessariamente o formato do trabalho de conclusão ou a visão pragmática da intervenção resultante da pesquisa. Concordamos com Nogueira, Neres e Brito (2016) quando afirmam que a intervenção decorrente da formação no MPE se refere muito mais ao processo de formação de professores pesquisadores que retornam para suas unidades escolares de maneira diferenciada, tendo construído uma visão ampliada da sua prática, da instituição escolar e de tudo aquilo que a ela se refere, tais como as questões relativas às políticas educacionais e curriculares, aos desafios da gestão e da avaliação escolar, tudo isso aliado à dimensão teórico-prática da formação e da prática docente.

Entre os egressos dessa primeira turma que são docentes do Ceeteps, verificou-se que dez atuam em escolas técnicas e dois, em Fatecs. Os docentes de outras instituições são oriundos do Sistema S, da Secretaria da Educação do Estado de São Paulo e da Universidade Paulista (Unip). Entre os não docentes, há aqueles vinculados a funções administrativas em ambiente educacional (três), em órgão de pesquisa (um), e no mundo corporativo (três).

Dentre as 23 dissertações defendidas, dado que ocorreram duas desistências, 14 encontram-se na linha de Formação do Formador, enquanto nove na de Gestão e Avaliação. Em função da amplitude dessas linhas, é interessante observar a diversidade dos trabalhos, que acabam mais bem compreendidos a partir dos respectivos grupos de pesquisas constituídos, observando-se uma concentração de trabalhos alinhados ao grupo de Fundamentos e Práticas da Educação Profissional. Existindo, como já foi demonstrado, a predominância de docentes, observou-se 
que a maioria deles desenvolveu temáticas direcionadas ao ensino técnico (dez dissertações), havendo também grande número de trabalhos voltados especificamente ao ensino tecnológico (sete dissertações). Os demais estudos versaram sobre temas diversos, como: educação corporativa (SILVA JR., 2017; SILVEIRA PINTO, 2017), parcerias estratégicas entre empresa e escola técnica (SILVA, 2017), formação profissional no ensino superior (ANTAS, 2017), comunidades de práticas de professores (DOMINGUES, 2017) e práticas docentes na rede pública estadual de ensino (RUFINO, 2017).

De qualquer forma, mesmo entre os não docentes, a ênfase da temática das dissertações foi sobre a educação técnica ou tecnológica em contextos escolares, totalizando, então, 21 dissertações com contribuições nesse assunto. Considerando que a maioria dos mestrandos são docentes vinculados à EPT, a maioria dos trabalhos tratou de questões relativas ao ensino nas unidades escolares do Ceeteps, aparecendo também trabalhos que apresentam e discutem concepções e práticas educativas em instituições como o Senai (Serviço Nacional de Aprendizagem Industrial) (BRAGA, 2017; GONÇALVES, 2017), IFSP (OLIVEIRA, 2017b), Unip (ANTAS, 2017) e escola estadual de ensino fundamental (RUFINO, 2017).

Há múltiplas possibilidades de analisar as dissertações concluídas pelos mestrandos da turma de 2015. Uma outra maneira de compreender como foram concebidas é perceber como a maioria delas estabelece discussões e propostas teórico-práticas para o universo da EPT enquanto política educacional específica, exigindo estratégias próprias de gestão e avaliação, além dos estudos permanentes sobre educação, trabalho e tecnologia. Dessa percepção, é possível destacar dissertações que abordam a necessária profissionalização docente como um processo dinâmico entre formação e exercício profissional (PEDRETTI, 2017; RIBEIRO, 2017; RUFINO, 2017), a gestão educacional (TRAMONTE, 2017; CROCE, 2017), as políticas institucionais (ARCANJO, 2017), a compreensão do fenômeno da evasão (CARBONARI, 2017; FEITOZA, 2017), a problematização das concepções e práticas de ensino na EPT considerando estudos sobre egressos (MATA, 2016; OLIVEIRA, 2017b), a educação 
integrada (TEIXEIRA, 2017), a relação com outros tipos de formação (MATOS, 2017), além daqueles trabalhos que analisam e propõem estratégias de ensino que possam ser transformadoras no universo escolar (OLIVEIRA, 2017a; ANTONINI, 2017; CILLI, 2017; DIAS, 2017; GONÇALVES, 2017).

\section{CONSIDERAÇÕES FINAIS}

Os mestrados profissionais surgem com a expectativa de, num sentido amplo, ressignificar a EPT, associada historicamente a uma formação restrita e restritiva na perspectiva de uma oposição entre formação profissional e formação propedêutica. Essa ressignificação também se espera num sentido estrito quanto à formação dos docentes que atuam nas escolas técnicas e tecnológicas, na medida em que os mestrados profissionais se configuram como uma modalidade de pós-graduação em educação profissional.

No caso específico de um MPE com enfoque em educação profissional, há ainda o compromisso de contribuir com a verticalização dos estudos sobre a profissionalização num contexto amplo das relações entre educação, trabalho e tecnologia.

Há que se discutir e estudar a visão superficial de que o profissional capacitado para atuar no mundo do trabalho está preparado para a docência simplesmente por dominar conteúdos técnicos. A formação técnica e profissional de um candidato à docência como principal fator de sua inserção na escola implica uma visão muito simplificada do que é o universo escolar e de qual é o papel do docente nesse universo. Também não é possível ignorar que inúmeros profissionais das mais diversas áreas atuam na docência sem que tenham passado por cursos de formação docente (TARDIF, 2000; SCHÖN, 2000). A ênfase exclusiva, e discutível, no notório saber (BRASIL, 2017) dos possíveis docentes para a EPT tem sido um fator controverso recorrente na história dessa modalidade de ensino.

Ignorar que os indivíduos e as organizações em situações e contextos não escolares desenvolvem concepções e estratégias de formação profissional também não nos faz avançar. Um programa de MPE numa instituição historicamente 
vinculada à EPT coloca desafios específicos para o cenário da pós-graduação e é o que tentamos demonstrar ao longo deste estudo.

A formação profissional em contextos não escolares e a ênfase na formação técnica e tecnológica não faz desse Programa algo distanciado da formação docente, já que, como vimos, o atendimento à demanda interna prevista no seu projeto inicial tem sido a marca no processo de seleção dos candidatos e na elaboração das dissertações de seus egressos. Embora o Programa esteja aberto a docentes de outras instituições de EPT e a candidatos oriundos do setor produtivo, o que ocorre é que, seja pela vinculação institucional, seja pela temática das pesquisas e das dissertações de seus egressos, o atendimento a uma demanda interna tem proporcionado ao programa contribuir com a formação de professores, gestores e funcionários administrativos do Ceeteps.

Espera-se que este estudo possa potencializar o necessário intercâmbio e reconhecimento mútuo entre diferentes programas de MPEs, especialmente aqueles ainda poucos que têm enfoque em EPT. As diretrizes para os mestrados profissionais são importantes porque os regulamentam e traçam seus contornos, mas a produção e publicação de artigos relacionados às experiências institucionais singulares quanto a essa modalidade de pós-graduação contribuem não só para a divulgação do que tem sido feito, mas também para a construção coletiva desses mestrados em processo de implementação e consolidação.

Como um desdobramento deste estudo, é possível produzir e difundir o conhecimento e a valorização do Programa de Mestrado Profissional em Gestão e Desenvolvimento da Educação Profissional do Ceeteps. No entanto, esse é, sobretudo, um exercício de autoavaliação a partir do levantamento e da reflexão sobre as concepções que nortearam a sua implementação diante das circunstâncias e possibilidades que se apresentam em sua trajetória nesses primeiros três anos de existência. 


\section{REFERÊNCIAS}

ALMEIDA, L. A. Produção de livros didáticos no mestrado profissional de História: relato de experiência a partir de uma disciplina da UFRB. Revista História Hoje, São Paulo, v. 5, n. 9, p. 221-248, jan.jjun. 2016.

ANDRÉ, M.; PRINCEPE, L. O lugar da pesquisa no Mestrado Profissional em Educação. Educar em Revista, Curitiba, n. 63, p. 103-117, jan./mar. 2017.

ANTAS, A. G. Formação e capacitação em propaganda e marketing. 2017. 167 f. Dissertação (Mestrado Profissional em Gestão e Desenvolvimento da Educação Profissional) - Ceeteps, São Paulo, 2017.

ANTONINI, R. E. D. A camada narrativa do design de jogos no ensino gamificado: um experimento no âmbito do ensino profissional. 2017. 88 f. Dissertação (Mestrado Profissional em Gestão e Desenvolvimento da Educação Profissional) - Ceeteps, São Paulo, 2017.

ARCANJO, C. R. O. Projeto educacional das classes descentralizadas no atendimento à formação de demandas específicas: um estudo sobre a experiência do Centro Paula Souza. 2017. 62 f. Dissertação (Mestrado Profissional em Gestão e Desenvolvimento da Educação Profissional) - Ceeteps, São Paulo, 2017.

BRAGA, A. B. R. As competições de educação profissional: experiências do Senai São Paulo. 2017. 125 f. Dissertação (Mestrado Profissional em Gestão e Desenvolvimento da Educação Profissional) - Ceeteps, São Paulo, 2017.

BRASIL. Lei de Diretrizes e Bases da Educação Nacional. Lei n. 13.415, de 16 de fevereiro de 2017. Brasília, DF, 2017. Disponível em: <http://www.planalto.gov. br/ccivil_03/_ato2015-2018/2017/lei/L13415.htm>. Acesso em: 10 jun. 2017.

CAMPOS, M. A. T.; GUÉRIOS, E. Mestrado profissional e educação: reflexões acerca de uma experiência de formação à luz da autonomia e da profissionalização docente. Educar em Revista, Curitiba, n. 63, p. 35-51, jan./mar. 2017.

CARBONARI, H. O. Análise da evasão nos cursos superiores de tecnologia de FATECs: um estudo baseado na medida de efetividade. 2017. 144 f. Dissertação (Mestrado Profissional em Gestão e Desenvolvimento da Educação Profissional) - Ceeteps, São Paulo, 2017.

CENTRO ESTADUAL DE EDUCAÇÃO TECNOLÓGICA PAULA SOUZA. Proposta do programa do mestrado profissional em educação. Unidade de Pós-graduação. São Paulo: Ceeteps, 2013.

CENTRO ESTADUAL DE EDUCAÇÃO TECNOLÓGICA PAULA SOUZA. Perfil e histórico. 2017. Disponível em: <http://www.cps.sp.gov.br/perfil-e-historico/>. Acesso em: 8 set. 2017.

CILLI, T. L. B. 0 design como saber transversal na formação profissional e tecnológica. Dissertação (Mestrado Profissional em Gestão e Desenvolvimento da Educação Profissional) - Ceeteps, São Paulo, 2017.

COORDENAÇÃO DE APERFEIÇOAMENTO DE PESSOAL DE NÍVEL SUPERIOR - CAPES. Portaria normativa n. 17, de 28 de dezembro de 2009. 2009. Disponível em: <https://www.capes.gov.br/images/stories/download/legislacao/ PortariaNormativa_17MP.pdf $>$. Acesso em: 9 jun. 2017. 
CROCE, E. F. A educação profissional empreendedora - estratégias de gestão no ensino técnico de nível médio com foco no empreendedorismo - estudo de caso. 2017. 162f. Dissertação (Mestrado Profissional em Gestão e Desenvolvimento da Educação Profissional) - Ceeteps, São Paulo, 2017.

CUNHA, C. M.; AGRANIONIH, N. T. Mestrado profissional em educação: teoria e prática de ensino - qualificação dos processos de educar na pesquisa da Educação Básica. Educar em Revista, Curitiba, n. 63, p. 119-135, jan./mar. 2017.

DIAS, M. G. S. Educação profissional: uma abordagem do inglês instrumental sintonizada com a proposta do curso técnico em turismo do Centro Paula Souza. 2017. 61 f. Dissertação (Mestrado Profissional em Gestão e Desenvolvimento da Educação Profissional) - Ceeteps, São Paulo, 2017.

DOMINGUES, I. Formação docente em comunidades de prática: um estudo com professores de educação profissional e tecnológica de uma instituição educacional em São Paulo. 2017. 185 f. Dissertação (Mestrado Profissional em Gestão e Desenvolvimento da Educação Profissional) - Ceeteps, São Paulo, 2017.

FEITOZA, A. S. Fatores de evasão na Educação Profissional Tecnológica: um estudo baseado no olhar do aluno evadido. 2017. 134 f. Dissertação (Mestrado Profissional em Gestão e Desenvolvimento da Educação Profissional) Ceeteps, São Paulo, 2017.

FIALHO, N. H.; HETKOWSKI, T. M. MPEs: novas perspectivas da pós-graduação no cenário brasileiro. Educar em Revista, Curitiba, n. 63, p. 19-34, jan./mar. 2017.

FISCHER, T. Mestrado profissional como prática acadêmica. Revista Brasileira de Pós-Graduação, Brasília, DF, v. 2, n. 4, p. 24-29, jul. 2005.

FÓRUM NACIONAL DE COORDENADORES DE PROGRAMAS DE PÓS-GRADUAÇÃO EM EDUCAÇÃO - FORPRED. Relatório das condições e perspectivas dos mestrados profissionais na área de educação. Goiânia, 29 de setembro de 2013. Disponível em: <http://www.anped.org.br/sites/default/ files/relatorio_comissao_forpred_2013.pdf>. Acesso em: 10 jun. 2017

GONÇALVES, M. B. Work-based learning aplicado ao curso de aprendizagem industrial de assistente administrativo da Escola Senai "Antonio Ermírio de Moraes”. 2017. 151 f. Dissertação (Mestrado Profissional em Gestão e Desenvolvimento da Educação Profissional) - Ceeteps, São Paulo, 2017.

HETKOWSKI, T. M.; DANTAS, T. R. Mestrados profissionais: a itinerância da área de educação e os legados da Universidade do Estado da Bahia. Revista da FAEEBA - Educação e Contemporaneidade, Salvador, v. 25, n. 47, p. 89-104, set./dez. 2016.

MACHADO, L. O desafio da formação dos professores para a EPT e PROEJA. Revista Educação e Sociedade, Campinas, v. 32, n. 116, p. 689-704, jul./set. 2011. Disponível em: <http://www.scielo.br/pdf/es/v32n116/a05v32n116.pdf>. Acesso em: 20 jun. 2017.

MATA, M. A. Os egressos da educação profissional e tecnológica do eixo de gestão 
e negócios: relação entre tecnólogo e trabalho. 2016. 148 f. Dissertação (Mestrado Profissional em Gestão e Desenvolvimento da Educação Profissional) - Ceeteps, São Paulo, 2016.

MATOS, S. Bacharéis e tecnólogos da área de gerenciamento e administração graduados em instituições de ensino superior privadas em São Paulo. 2017. 99 f. Dissertação (Mestrado Profissional em Gestão e Desenvolvimento da Educação Profissional) - Ceeteps, São Paulo, 2017.

NOGUEIRA, E. G. D.; NERES, C. C.; BRITO, V. M. de. Mestrado profissional em educação: a constituição do professor/pesquisador e o retorno para a escola. Revista da FAEEBA - Educação e Contemporaneidade, Salvador, v. 25, n. 47, p. 63-75, set./dez. 2016.

OLIVEIRA, G. B. Educação a distância e aprendizagem significativa: o uso de organizadores prévios de memória em materiais instrucionais multimídia. 2017. 114 f. Dissertação (Mestrado Profissional em Gestão e Desenvolvimento da Educação Profissional) - Ceeteps, São Paulo, 2017a.

OLIVEIRA, S. R. Empregabilidade, cidadania e juventude: um estudo sobre os egressos do ensino técnico integrado ao médio do Instituto Federal de Educação, Ciência e Tecnologia de São Paulo (IFSP - Câmpus SP) entre 2011-2015. 2017. 142 f. Dissertação (Mestrado Profissional em Gestão e Desenvolvimento da Educação Profissional) - Ceeteps, São Paulo, 2017b.

PEDRETTI, R. G. A prática docente e a compreensão de textos na educação profissional: o letramento como suporte. 2017. 65 f. Dissertação (Mestrado Profissional em Gestão e Desenvolvimento da Educação Profissional) Ceeteps, São Paulo, 2017.

PETEROSSI, H. G.; MENINO, S. E. A formação do formador. São Paulo: Centro Paula Souza, 2017. (Coleção Fundamentos e Práticas em Educação Profissional e Tecnológica, v. 10).

RIBEIRO, T. M. M. A formação docente na educação profissional e tecnológica a partir de narrativas de professores das escolas técnicas do Centro Paula Souza. 2017. 98 f. Dissertação (Mestrado Profissional em Gestão e Desenvolvimento da Educação Profissional) - Ceeteps, São Paulo, 2017.

ROMÃO, J. E.; MAFRA, J. F. Mestrado profissional: crônica de uma morte anunciada. Revista Plurais, Salvador, v. 1, n. 2, p. 10-23, abr./ago. 2016.

RUFINO, I. A. M. F. O docente e os fatores para a escolha da escola de atuação: um estudo em unidades de ensino da Diretoria Regional Sul I da cidade de São Paulo. 2017. 90 f. Dissertação (Mestrado Profissional em Gestão e Desenvolvimento da Educação Profissional) - Ceeteps, São Paulo, 2017.

SCHÖN, Donald. Educando o profissional reflexivo: um novo design para o ensino e a aprendizagem. Porto Alegre: Artes Médicas Sul, 2000.

SILVA JR., A. S. A. H. A perspectiva dos policiais militares do Estado de São Paulo quanto à contribuição da Rede de Ensino a Distância da Secretaria Nacional de Segurança Pública para o seu desempenho profissional. 2017. 101 f. Dissertação (Mestrado Profissional em Gestão e Desenvolvimento da Educação Profissional) - Ceeteps, São Paulo, 2017. 
SILVA, L. F. Parcerias educacionais como fator de transferência de tecnologia e conhecimento entre empresas e instituições de ensino: relato de experiência. 2017. 136 f. Dissertação (Mestrado Profissional em Gestão e Desenvolvimento da Educação Profissional) - Ceeteps, São Paulo, 2017.

SILVEIRA PINTO, L. Ações de treinamento para líderes de call center: um estudo de caso. 2017. 93 f. Dissertação (Mestrado Profissional em Gestão e Desenvolvimento da Educação Profissional) - Ceeteps, São Paulo, 2017.

SOUSA, C. P. de; PLACCO, V. M. de. Mestrados profissionais na área de educação e ensino. Revista da FAEEBA - Educação e Contemporaneidade, Salvador, v. 25, n. 47, p. 23-35, set./dez. 2016.

TARDIF, M. Saberes profissionais dos professores e conhecimentos universitários: elementos para uma epistemologia da prática profissional dos professores e suas consequências em relação à formação para o magistério. Revista Brasileira de Educação, Rio de Janeiro, v. 3, n. 13, jan./abr. 2000. Disponível em: < http://www.anped.org.br/rbe/rbedigital/ RBDE13/RBDE13_05_MAURICE_TARDIF.pdf>. Acesso em: 1 nov. 2017.

TEIXEIRA, L. L. Ensino técnico integrado ao médio: contextualização histórica e desafios para a formação docente. 2017. 88 f. Dissertação (Mestrado Profissional em Gestão e Desenvolvimento da Educação Profissional) Ceeteps, São Paulo, 2017.

TRAMONTE, A. T. F. S. Burocracia: a concepção gestora nas Faculdades de Tecnologia do Estado de São Paulo. 2017. 98f. Dissertação (Mestrado Profissional em Gestão e Desenvolvimento da Educação Profissional) Ceeteps, São Paulo, 2017.

Recebido em: 17 OUTUBRO 2017

Aprovado para publicação em: 3 AGOSTO 2018

(C) Este é um artigo de acesso aberto distribuído nos termos da licença Creative BY NC 